\title{
Achieving bankable green deals in the commercial sectors of emerging economies: the case of shopping malls in the United Arab Emirates
}

\author{
H. Taleb ${ }^{1} \&$ Y. Al-Saleh ${ }^{2}$ \\ ${ }^{1}$ Faculty of Engineering, British University in Dubai, UAE \\ ${ }^{2}$ INSEAD Innovation and Policy Initiative, Abu Dhabi
}

\begin{abstract}
The United Arab Emirates (UAE) is known for having one of the world's highest per capita carbon rates. In recent years, however, the UAE has launched a number of sustainability-oriented initiatives with the ultimate aims of both reducing its carbon footprint and greening the image of the country. Most efforts have focused, thus far, on government-led large-scale renewable energy projects. Meanwhile, there is a growing global understanding that as governments have limited financial capacities, a large proportion of green investment is slated to come from the private sector. Given the potential role of the business community in achieving the overreaching aims of sustainable development, this paper examines ways of achieving bankable win-win green deals in one of the UAE's fastest growing sectors; the commercial sector. Through conducting in-depth interviews and surveys with several retail owners in the UAE, we examined both their current willingness to engage in green entrepreneurial activities and ways to enhance their contribution to achieving a sustainable future for the commercial sector in the UAE. A particular focus was placed on examining the potential of striking win-win deals that involve the incorporation of renewable energy technologies and energy-efficient equipment in shopping malls.

Keywords: green deals, green entrepreneurship, commercial buildings, UAE.
\end{abstract}




\section{Introduction}

There is widespread agreement that the cost of mitigating climate change is a significant fiscal issue across the globe $[1,2]$. As governments have limited financial capacity, a large proportion of the required green investment to address this issue is expected to come from the private sector. Given the high upfront investment usually associated with green energy technologies, a range of innovative business models have emerged to tap into these potentially lucrative green markets $[3,4]$. In fact - in line with the concept of 'shared value' that was proposed by Porter and Kramer [5] - there is growing recognition that since the competitiveness of businesses and the health of its community are mutually dependent, business owners should focus on creating economic value in a way that also creates social benefit.

Against this backdrop, this paper highlights the importance of green business model innovation and its potential for greening the commercial sectors of emerging economies through considering the case of the UAE. More specifically, several retail owners in the UAE have been interviewed and surveyed to examine their willingness to engage in green entrepreneurial activities do achieve win-win deals involving the incorporation of renewable energy technologies and energy-efficient equipment in one of the shopping malls in the UAE. This research paper is structured as follows: the case of the UAE is introduced first, before describing the adopted research methodology. Following this, the empirical findings are discussed before providing recommendations on how best to implement green deals across the commercial building sector.

\section{A literature-based examination of the case of the UAE}

On the global stage, the built environment is responsible for approximately $40 \%$ of total primary energy consumption. As a young emerging economy, the UAE has been relatively late in implementing energy conservation in its buildings. Inferior building practices and artificially cheap energy prices have led to wasteful levels of energy consumption. This, along with the harsh weather conditions in the UAE, has resulted in the country being ranked in the top ten countries in terms of electricity usage per capita and the second highest in terms of $\mathrm{CO}_{2}$ emissions per capita [6]. Higher electricity consumption does not only translate to higher electricity bills to the consumer - which are, however, largely subsidised - but it also forces utilities to invest in new power plants at a much faster rate. In Dubai, the utilities rely on imported natural gas to power most power stations, which causes further economic burden on the government [7].

Abu Dhabi - the capital city of the UAE - has been pioneering clean energy initiatives in the country. In 2006, Masdar was established to spearhead the establishment of a clean energy industry in Abu Dhabi. Masdar's clean energy projects include 'Shams 1' a 100MW concentrated solar power project with Abengoa Solar and Total in the western region of Abu Dhabi; Masdar City's 10MW solar PV array and Masdar City's 1MW rooftop installations. In addition, plans for a $100 \mathrm{MW}$ photovoltaic plant in $\mathrm{Al}$ Ain are at an advanced stage, as is 
the development of a 30MW onshore wind farm on Sir Bani Yas Island [8]. In October 2013, the Dubai Government launched its 13 MW solar photovoltaic plant as part of a planned solar complex with an output capacity of $1 \mathrm{GW}$ by 2030. As part of this future complex - named the Mohammed Bin Rashid Al Maktoum Solar Park' - a 200MW solar plant is expected to start supplying electricity by April 2017. It will be the biggest such facility in the Middle East and North Africa [9]

On the regulatory front, Dubai - the most populous city in the UAE - is set to become the first major rooftop market in the region. In December 2014, a law was passed to allow PV rooftop systems to operate under a net-metering scheme in Dubai [10]. Such a policy development is expected to jump-start the distributed generation market in Dubai. In fact, there is some emerging evidence that government support - although modest when compared with many advanced countries - has already managed to whet the appetite of eco-entrepreneurs in the UAE [3]. Other empirical evidence suggests that the UAE is a regional leader when it comes to informed public awareness with regard to sustainability [11]. Therefore, exploring the potential for the emergence of UAE-based green entrepreneurs - who would be interested in achieving bankable green deals whilst solving environmental problems - is both timely and appropriate.

\section{Research methodology}

This piece of research carried out an empirical examination, the aim of which was to examine the potential to embark on green bankable deals in the UAE's commercial building sector. A fifteen-year-old mall in Dubai was chosen to act as the case study for this study. The mall owners, managers and retailers were presented with a green business proposition and then asked about the likelihood of their pursuit of this idea. Five interviews were conducted with mall owners/managers, sixty five retailers were surveyed and the collective results were analysed in a qualitative manner. It is believed that adopting such a qualitative research approach is advantageous in terms of providing an in-depth examination of situations in which complex questions are posed [12].

The chosen green idea was a simple one; it involves the mall owners taking the initiative to install solar rooftops and energy-efficient equipment at their own expense. As a result of making this green investment, retailers would observe savings in their monthly utility bills. Half of the resultant savings have to be paid back to the mall owners for a period that is double the payback period. For instance, assuming that the mall owners manage to pay their green investment back in one year, the retailers would be obliged to keep paying a fifty per cent share of their savings for a second year. Such an arrangement could achieve a win-win deal for both the mall owners and retailers. It could also provide a solution to a common problem known as the 'landlord/tenant dilemma' - as the former is not usually incentivised to invest in energy-efficient equipment whilst the latter is the party that will usually end up paying the energy bills and hence benefiting from any savings [13]. Thus, at least in theory, this green proposition could result in both tangible and non-tangible benefits - such as improving the 
image of the mall - that could further encourage others to engage in green business activities. To examine the potential success of this idea in practice, we embarked on an empirical investigation, the results of which are detailed next.

\section{Empirical findings}

The research findings - derived from surveying retailers and interviewing mall owners/managers - indicate that the success of green deals is influenced by a set of hindering factors (barriers) that could affect its potential for fruition. A large number of barriers emerged; such factors can be classified as either technical or non-technical factors.

With regard to technical barriers, more than seventy per cent of the research participants mentioned that although they admire the 'theoretical' attractiveness of the green proposition, they admitted a lack of technical capacity to assess electricity saving potential. Around half of them identified the non-existence of supporting infrastructure in the mall as a key hindrance. Moreover, a substantial number stated that they were unaware of any previous studies that have examined this particular deal or they had not heard about such projects in the UAE and did not know of any sources for the relevant data necessary to assess its viability. In addition, some of the surveyed retailers and interviewed mall owners/managers admitted a lack of the technical calibre needed to operate and maintain the new equipment. A few of the participants indicated a lack of trust in the technical capabilities of local equipment suppliers and some went even went further and expressed concern over potential safety hazards. In effect, such concerns reflect a degree of unfamiliarity with renewable energy and energyefficient equipment. Table 1 lists all the technical barriers that were mentioned during the interviews and surveys.

Table 1: Technical barriers to implementing green deals in commercial buildings.

\begin{tabular}{|c|c|}
\hline Technical barriers & $\mathbf{N}^{*}$ \\
\hline - Uncertainty with regard to electricity saving potential & 51 \\
\hline $\begin{array}{l}\text { - Absence of supportive infrastructure for installing renewable } \\
\text { energy technologies in buildings }\end{array}$ & 33 \\
\hline - Unviability of technical feasibility studies & 26 \\
\hline $\begin{array}{l}\text { - Lack of the technical competence needed for operating and } \\
\text { maintaining the equipment }\end{array}$ & 19 \\
\hline $\begin{array}{l}\text { Lack of trust in the technical capabilities of local green } \\
\text { equipment suppliers }\end{array}$ & 4 \\
\hline - Concern over potential safety risks & 3 \\
\hline
\end{tabular}

${ }^{*} \mathbf{N}$ is the number of research participants who identified a technical barrier. 
Table 2 lists identified barriers that could be regarded as non-technical factors. From the perspective of retailers, 'uncertainty' was the recurring theme in the surveys. For example, there was uncertainty with regard to the prospects of their future leases in the same mall, as well as some anxiety with regard to the legality of such deals and the protection of their own rights. On the other hand, obstacles pointed out by the interviewed mall owners/managers include high capital costs and a long payback period due to highly-subsided electricity tariffs. This was in addition to worries over securing the needed approval from the authorities as well as the commitment of the retailers.

Table 2: Non-technical barriers to implementing green deals in commercial buildings.

\begin{tabular}{|c|c|c|}
\hline & Non-technical barriers & $\mathbf{N}^{*}$ \\
\hline \multirow{4}{*}{$\begin{array}{l}\text { Retailers } \\
\text { (total of 65) }\end{array}$} & - Doubts about continuity in the same mall & 47 \\
\hline & $\begin{array}{l}\text { Uncertainty with regard to the legality of this } \\
\text { type of deal }\end{array}$ & 32 \\
\hline & - Concern over rights protection & 31 \\
\hline & - Change resistance and a risk-averse culture & 10 \\
\hline \multirow{5}{*}{$\begin{array}{l}\text { Mall owners/ } \\
\text { managers } \\
\text { (total of 5) }\end{array}$} & - $\quad$ High capital cost & 5 \\
\hline & $\begin{array}{l}\text { - Uncertainty with regard to the commitment } \\
\text { of retailers }\end{array}$ & 4 \\
\hline & $\begin{array}{l}\text { Doubts over getting needed approval from } \\
\text { authorities }\end{array}$ & 4 \\
\hline & - Long payback period & 4 \\
\hline & - $\quad$ Subsidised electricity tariffs & 3 \\
\hline
\end{tabular}

" $\mathbf{N}$ is the number of research participants who identified a non-technical barrier.

The research participants were also asked to suggest ways to overcome the various barriers that they had identified. Despite there being a rather negative view with regard to the prospects for green deals in commercial buildings in the UAE, they suggested a number of valuable recommendations that might boost the viability of such deals. Generally speaking, their contribution towards identifying potential barriers was not as comprehensive as their ability to highlight barriers. All in all, it was strongly suggested that government support either through providing direct financial support or setting up supportive regulations - was a vital element in promoting green entrepreneurship in the commercial sector. Other potential enablers include conducting awareness campaigns and securing buy-in from banks. Table 3 exemplifies recommended enablers in the commercial sector of the UAE. 
Table 3: Enablers to achieve bankable green deals in the commercial sector.

\begin{tabular}{|c|c|}
\hline Enablers & $\mathbf{N}^{*}$ \\
\hline - Governmental support for the sustainability agenda & 39 \\
\hline - $\quad$ Setting up a regulatory framework that encourages such deals & 37 \\
\hline - $\quad$ Obtaining a buy-in from banks & 17 \\
\hline - $\quad$ Marketing campaigns to raise awareness of such deals & 17 \\
\hline $\begin{array}{l}\text { - Dialogue between mall owners and retailers to agree on the } \\
\text { specifics of the deal and promote transparency between them } \\
\text { in general }\end{array}$ & 3 \\
\hline $\begin{array}{l}\text { Focus on established business retailers who might be } \\
\text { interested in long-term investment }\end{array}$ & 2 \\
\hline
\end{tabular}

${ }^{*} \mathbf{N}$ is the number of interviewees who identified an enabler.

\section{Conclusions}

Our research has identified several key barriers as well as potential enablers to implementing bankable green deals in the commercial sector of the UAE. The biggest show-stoppers appear to be a lack of awareness and a prevailing opportunistic attitude that focuses on maximising short-term profit. Apparently striking green deals, despite their theoretical attractiveness, is not going to be an overnight success. In order to make them a success, all relevant stakeholders including owners/management teams, retailers, governments and local banks must collaborate and adopt a long-term perspective. For green entrepreneurship to flourish in the commercial sector of the UAE there is a need for a mind-set shift to adopt a regard for others as opposed to a self-interested business mentality.

\section{Acknowledgement}

The authors would like to thank "MUSTADAMA Ltd. Sustainable Solutions" in Masdar City-Abu Dhabi for sponsoring this paper to be presented in the "Sustainable Development and Planning Conference" held in Istanbul in May 2015.

\section{References}

[1] International Energy Agency. Redrawing the Energy-Climate Map, IEA: Paris, 2013.

[2] Sustainable Energy for All, United Nations, http://www.sustainable energyforall.org/about-us 
[3] Al-Saleh, Y.M. \& Mahroum, S., A critical review of the interplay between policy instruments and business models: greening the built environment a case in point. Journal of Cleaner Production, in Press, 2015.

[4] World Economic Forum 'WEF', The Green Investment Report: The Ways and Means to Unlock Private Finance for Green Growth, WEF: Geneva, 2013.

[5] Porter, M. \& Kramer, M.R., Creating shared value. Harvard Business Review, January 2011.

[6] Al-Sallal, K., Al-Rais, L. \& BnDalmouk, M, Designing a sustainable house in the desert of Abu Dhabi. Proc. of the World Renewable Energy Congress XI, Abu Dhabi, pp. 25-30, 2010.

[7] Dubai Electric and Water Authority, http://www.dewa.gov.ae/community/ conservation/ydc/savepower.aspx

[8] Masdar, http://www.masdar.ae/en/masdar/detail/launched-by-the-abudhabi-leadership-in-2006-with-the-mission-to-advance-re

[9] Graves, L., The National, http://www.thenational.ae/business/energy/ tender-for-second-phase-of-mohammed-bin-rashid-solar-park-in-dubaiwon-by-saudi-consortium

[10] Gifford, J., PV Magazine, http://www.pv-magazine.com/news/details/ beitrag/emerging-markets-2015--dubais-commercial-rooftop-segmenttarget-for-new-uae-scheme_100017666/\#axzz3OzDntUNE

[11] Ghazal-Aswad, N., Al-Saleh, Y.M. \& Taleb, H., Clean energy awareness campaigns in the UAE: an awareness promoters perspective. Int. J. of Innovation and Knowledge Management in MENA, 2(2), pp. 131-156, 2012.

[12] Hamby, J.L., Oklahoma State University, http://www.okstate.edu/ag/ agedcm4h/academic/aged5980a/5980/qualrsch/ QUALRSCH/sld001.htm

[13] Gillingham, K., Harding, M. \& Rapson, D. Split incentives in residential energy consumption. Energy Journal, 33(2), pp. 37-62, 2012. 